\title{
Work in Progress: Pilot Shadowing Experiences to Introduce Engineering Students to Speech-Language Pathology
}

\section{Dr. Todd Freeborn, The University of Alabama}

Todd Freeborn, $\mathrm{PhD}$, is an assistant professor with the Department of Electrical and Computer Engineering at The University of Alabama. His current research focuses on techniques to collect and analyze the electrical impedance of biological tissues and their potential applications.

\section{Dr. Memorie Gosa, The University of Alabama}

Memorie M. Gosa is a pediatric speech-language pathologist and board certified specialist in swallowing and swallowing disorders. She is an assistant professor at The University of Alabama and maintains a clinical caseload at The University of Alabama Speech and Hearing Center and Druid City Hospital's Neonatal Intensive Care Unit. Dr. Gosa has published and presented nationally and internationally on the topic of pediatric dysphagia diagnosis and management. Her research focuses on establishing the efficacy of common diagnostic and treatment methods used in the assessment and management of pediatric dysphagia. 


\section{Work-in-Progress: Pilot Shadowing Experiences to Introduce Engineering Students to Speech-Language Pathology}

\section{Introduction}

Speech language pathology is an applied behavioral science with a scope of practice that includes screening, assessment, treatment, and technology/instrumentation related to the areas of fluency, speech production, language, cognition, voice, resonance, feeding and swallowing, and auditory habilitation/rehabilitation [1]. Speech-language pathologists (SLPs) receive hundreds of hours of clinical training involving direct patient care. SLPs are keenly aware of the many ways that technology can be applied to improve outcomes for patients with speech, language, voice, and swallowing problems. Their training however does not provide the technical knowledge and experiences to design and implement technologies to support their clinical practice and patients. In contrast, engineering students receive intensive training that prepares them to design, develop, and evaluate technologies, but often not the personal interactions necessary to understand the needs of patients and clinicians. Without these interactions, students from each major fail to recognize the discipline specific 'language' or understand the complementary skillsets offered by the other major. This creates a barrier to collaboration to improve diagnostic accuracy and therapeutic outcomes within the field of speech language pathology. To begin to address the disconnects between these fields, faculty from the Departments of Electrical and Computer Engineering and Communicative Disorders at The University of Alabama (UA) piloted shadowing experiences for engineering students. These experiences had engineering students observe clinicians and studentclinicians at the Speech and Hearing Center (SHC) during typical therapy sessions with community clients and reflect on their experiences. In this work, an overview of the logistical elements, a summary of the student feedback from the written reflections and focus groups, and future recommendations for the program are presented.

\section{Speech Pathology Shadowing Sessions}

Shadowing and clinical placements are a key part of healthcare professional education [2] and we believe that engineering students will also benefit from observation and interaction with groups outside of their discipline. This is supported by recent experiences reported on inter-professional shadowing for senior medical students [3] and clinical immersion of engineering students [4]-[6]; which showed positive results for improving students understanding and appreciation of other disciplines. This provides the motivation for this pilot program, to introduce engineering students to speech language pathology through clinical shadowing experiences. For this pilot, 8 engineering students were recruited from the pool of students involved in research with Dr. Freeborn. Their participation was voluntary, not a component of any formal course, and based solely on each students interest in learning about speech pathology practice to complement their course-work and research. This pilot cohort consisted of graduate electrical (2), undergraduate electrical (3), and undergraduate mechanical (3) engineering students.

HIPPA Training: Before the shadowing sessions, the clinical director of the SHC met with all participating students to train them about the Health Insurance Portability and Accountability Act (HIPPA) and confidentiality requirements. This training established the policies and requirements to participate in these clinical teaching experiences regarding access to medical records, discussion of clinically sensitive information, and engaging with clients and caregivers. While standard training for speech-pathology students, it is not a typical training activity for our engineering students but is critical for them to understand clinical requirements. After this training each student was scheduled for two 1-hour observation sessions. These sessions fell into four categories with descriptions provided in Table 1. 
Table 1: Description of speech-pathology therapies observed during pilot program

\begin{tabular}{|c|c|}
\hline Therapy & Description \\
\hline Articulation & $\begin{array}{l}\text { - Clients across the lifespan may present with speech sound disorders that } \\
\text { affect the intelligibility of their speech. Treatment includes training or } \\
\text { retraining appropriate motor speech patterns to improve intelligibility. }\end{array}$ \\
\hline $\begin{array}{l}\text { Lee Silverman } \\
\text { Voice Treatment } \\
\text { (LVST) }\end{array}$ & $\begin{array}{l}\text { A program to treat voice disorders associated with Parkinson's disease. } \\
\text { The program is designed to increase vocal loudness and reduce } \\
\text { concomitant vocal problems. }\end{array}$ \\
\hline Fluency & $\begin{array}{l}\text { - Persons who stutter may seek to improve their speech fluency with } \\
\text { treatment focused on changing the client's speech to facilitate greater } \\
\text { periods of speech fluency. }\end{array}$ \\
\hline Motor Speech & $\begin{array}{l}\text { Motor speech disorders include dysarthria and apraxia and both result } \\
\text { from neurological insult. Motor speech therapy presents a hierarchy of } \\
\text { graduated speech tasks and applies principals of motor learning to } \\
\text { improve a client's speech following neurologic injury. }\end{array}$ \\
\hline
\end{tabular}

Shadowing \& Reflection: For each session, students were tasked with (i) investigating the type of therapy they would be observing; (ii) recording details of the procedures and clinician/patient interactions during each session; and (iii) reflecting on why it is important for engineers to interact with clinicians and patients. Table 2 summarizes the common responses from the students written reflections.

Table 2: Summary of participant's responses to shadowing experience reflection questions

\begin{tabular}{|c|c|}
\hline Reflection Question & Summary of Responses \\
\hline $\begin{array}{l}\text { What was an interesting } \\
\text { aspect of this shadowing } \\
\text { experience for you? }\end{array}$ & $\begin{array}{l}\text { - Speed and proficiency of clinicians, their ability to simultaneously } \\
\text { execute a technical therapy session, adapt the session using patient } \\
\text { feedback, and communicate with their patients to keep them } \\
\text { engaged and at-ease. } \\
\text { - How complex the mechanics required for speech production are } \\
\text { (i.e. use of lips, tongue, teeth, breathing) } \\
\text { - How the same type of therapy (motor control) was modified to } \\
\text { accommodate the needs of patients in different age groups }\end{array}$ \\
\hline $\begin{array}{l}\text { Why is it important for } \\
\text { engineers to interact } \\
\text { with clinicians and } \\
\text { patients? }\end{array}$ & $\begin{array}{l}\text { - Engineers may not understand the exact needs of clinicians and } \\
\text { patients, and without this knowledge cannot even begin to support } \\
\text { them } \\
\text { - Engineers may not understand exactly how tools will be used by } \\
\text { clinicians and patients during therapy, which could limit their } \\
\text { actual usefulness after being developed } \\
\text { - Provides an opportunity to truly connect with the groups that } \\
\text { engineers are trying to support and observe the impact that } \\
\text { technologies or tools have on improving quality of life }\end{array}$ \\
\hline
\end{tabular}

Focus Group: A focus group was run with the participating students to review their experiences, present what they had learned, allow each student to learn about the types of therapy they were not able to observe, brainstorm how engineers can support clinicians, and discuss how the shadowing sessions could be improved for future iterations. During brainstorming, discussions regularly 
focused on the necessary usability of any tool or technology. As an example, one participant noted that while audio recordings could have been captured during therapy and used to evaluate changes over time between sessions, that a student-clinician indicated that setup and data collection of the microphone and software took too long when they were balancing a heavy clinical load and often interrupted the session if there were technical issues. An important realization of the group was that tools need to be developed to support existing clinical practice and that usability will be a driving factor for adoption. Another important outcome was the communicated enthusiasm by the undergraduate students to explore existing sensor technologies. They all identified having a gap in their own knowledge regarding what sensors were available to collect physiological measurements, but voiced excitement to learn about them. This could serve as a strong motivating factor for students to pursue courses or extra-curricular experiences (research experiences, student design competitions) to learn more about these topics.

\section{Lessons Learned and Future Plans}

Student Recommendations: Recommendations to improve future iterations included: (i) offering the shadowing as a component of a formal course (for credit towards their degrees) that introduces engineers to speech pathology, provides deeper descriptions of the physiology, therapies, and hands-on experience with the instruments; (ii) pairing engineers with student-clinicians who they could have asked questions pre- and post-observation; (iv) more detailed guiding questions to structure the sessions; and (iv) including multiple sessions with the same clients over time to observe changes that may result from the therapies.

Capstone Projects: Future iterations of this program will task students with identifying clinical needs from their shadowing experiences, propose a possible solution, and encourage them to pursue those solutions during their own Capstone Design courses. Capstone design projects are ubiquitous in engineering education, aimed at promoting practical and real-world projects during an undergraduate's education [7], [8]. The pairing of this shadowing experience with Capstone Design is expected to increase student engagement and satisfaction; supported by results from previous clinical immersions where students expressed their desire to move from needs evaluation to prototype development [5].

Experiences for Speech Pathologists: While our pilot focused on engineering students, future iterations should introduce shadowing experiences for speech-pathology students. For collaborations to develop between these groups, both groups must have a working knowledge of the other discipline. This is not accomplished with only engineers participating in clinical observations. Future iterations could pair student-clinicians with Capstone Design groups to collaborate during the design process, or integrate clinicians into engineering lab experiences that introduce basic sensors and physiology data collection (i.e. heart rates, electromyography) to increase their familiarity with these topics through hands-on experiences.

Evaluation \& Assessment: Future iterations will use online survey instruments to collect formative and summative data from clinicians and student-clinicians to improve how we prepare and integrate the engineering students into the shadowing sessions. Their feedback can also help identify how to support clinicians to learn about engineering and topics they would be interested in. Finally, as the program continues follow-up data needs to be collected to track if these experiences resulted in participants pursuing Capstone projects, graduate studies, or careers related to biomedical topics to assess and evaluate the wider impacts. A significant outcome of this shadowing is that one student who participated is currently pursuing a research project under the supervision of Dr. Freeborn and Dr. Gosa to investigate surface electromyography to characterize swallowing behavior. 


\section{References}

[1] American Speech-Language-Hearing Association, "Scope of practice in speech-language pathology," Communication Disorders Quarterly, 2007. [Online]. Available: www.asha.org./policy.

[2] M. O’Keefe, T. Burgess, S. McAllister, and I. Stupans, "Twelve tips for supporting student learning in multidisciplinary clinical placements," Medical Teacher, vol. 34, no. 11, pp. 883-7, 2012. doi:10.3109/0142159X.2012.700431

[3] D. M. Shafran, L. Richardson, M. Bonta, "A novel interprofessional shadowing initiative for senior medical students," Medical Teacher, vol. 37, no. 1, pp. 86-89, 2015. doi:10.3109/0142159X.2014.929099

[4] J. Kadlowec, T. Merrill, S. Sood, J. G. Ryan, A. Attaluri, and R. A. Hirsh, "Clinical immersion and team-based design: into a third year," in 2017 ASEE Annual Conference and Exposition, Columbus, OH, 2017. http://peer.asee.org/28040

[5] S. Stirling and M. Kotche, "Clinical Immersion Program for Bioengineering and Medical Students," in 2017 ASEE Annual Conference \& Exposition, Columbus, OH, 2017. http://peer.asee.org/28041

[6] P.D.P. Cavanagh, J. Tranquillo, "Diseases, Devices, and Patients : Exposing BME Students to the Patient Experience," in 2017 ASEE Annual Conference \& Exposition, Columbus, OH, 2017. http://peer.asee.org/28185.

[7] S. Howe and J. Wilbarger, "2005 National survey of engineering capstone design courses," in 2006 ASEE Annual Conference \& Exposition, Chicago, IL, 2006. http://peer.asee.org/1023

[8] S. Howe, "Where are we now? Statistics on capstone courses nationwide," Advances in Engineering Education, vol. 2, no. 1, pp. 1-27, 2010. 